\title{
Dissolution of subducted ocean carbonates and organic matter controls the carbon isotopic signature of the mantle wedge
}

S. Tumiati ${ }^{*}$, S. ReCCHIA ${ }^{2}$, L. REMUSAT ${ }^{3}$, C. TIRABOSCHI $^{4}$, D. A. SVERJENSKY ${ }^{5}$ AND S. POLI ${ }^{1}$

${ }^{1}$ Dipartimento di Scienze della Terra, Università di Milano, Italy (*correspondence: simone.tumiati@unimi.it)

${ }^{2}$ DiSAT, Università dell'Insubria, Italy

${ }^{3}$ Muséum national d'Histoire naturelle Paris, France

${ }^{4}$ Insitut für Mineralogie, Universität Münster, Germany

${ }^{5}$ Department of Earth \& Planetary Sciences, Johns Hopkins

University, USA

Open ocean sediments consist mainly of biogenic carbonates (calcite), opal (amorphous silica) and organic matter. Once subducted, some carbon leaches out from them by devolatilization/dissolution and it is transferred to the mantle wedge prompting metasomatism and/or partial melting. Eventually, carbon in the mantle is released back as $\mathrm{CO}_{2}$ in the atmosphere via arc magmatism, and its carbon isotopic signature is thought to reflect that of its deep source. We experimentally investigated the carbon isotopic exchange between volatile $\mathrm{CO}_{2}$ and sediments, relying on a model system containing graphite $\left(\sim 99 \%{ }^{12} \mathrm{C}\right)$ and labeled aragonite $\left(\sim 99 \%{ }^{13} \mathrm{C}\right)$, with and without the presence of silica (coesite), interacting with aqueous fluids beneath the arcs at $P=3 \mathrm{GPa}$, $T=700^{\circ} \mathrm{C}$ and $f \mathrm{O}_{2} \approx \mathrm{FMQ}$.

At the investigated conditions $\mathrm{CO}_{2}$ up to $17 \mathrm{~mol} \%$ is produced, mainly by irreversible oxidation of graphite. The initial isotopic composition of $\mathrm{CO}_{2}$, depleted in ${ }^{13} \mathrm{C}$, evolves rapidly towards very high ${ }^{13} \mathrm{C}$ values, reaching $>80 \%$ of the initial isotopic ratio of aragonite. On the basis of thermodynamic calculations, we infer that this is due to the exchange with aqueous $\mathrm{CaHCO}_{3}{ }^{+}$, suggesting continuous dissolution/precipitation (recrystallization) and negligible decarbonation of aragonite. The isotopic signature of volatiles released by the slab and interacting with the mantle wedge is therefore controlled by carbonates, even if the major process underlying the formation of $\mathrm{CO}_{2}$ is the oxidative dissolution of graphite. Our results challenge the assumption that the isotopic signature of carbon volatiles and of their source is coupled in a straightforward manner. Extrapolation to natural $\partial^{13} \mathrm{C}$ is in the range $-4 \%$ to $-9 \%$ for volatile $\mathrm{CO}_{2}$, which fits well with the isotopic composition of the upper mantle $\left(\partial^{13} \mathrm{C}\right.$ $\approx-5 \%$ ) 